\title{
THE STUDY OF CADMIUM UPTAKE BY WATER HYACINTH (EICHHORNIA CRASSIPES) USING A NATURAL MODELLING APPROACH
}

\author{
Tamara E. Romanova*1, Ludmila A. Belchenkoํㅜ, Olga V. Shuvaeva² ${ }^{2}$ Maria V. Kurbatova ${ }^{1}$ \\ ${ }^{1}$ Novosibirsk State University, Pirogova,2, Novosibirsk, 630090, Russia \\ ${ }^{2}$ Nikolaev Institute of Inorganic Chemistry, Siberian Branch of Russian Academy of Sciences, Academician Lavrent'ev Prospect, 3 , \\ Novosibirsk, 630090, Russia \\ *E-mail: romanova-toma@mail.ru,Tel: +7 38333012 59,Fax: +7 3833309489
}

\begin{abstract}
The results of the investigation on the accumulation of cadmium by water hyacinth, depending on the conditions of pollutant exposure and the presence of various additives are discussed. The main specialty of this study is that all the experiments were carried out in natural conditions using the approach based on the application of the capacities called minicosms. It allowed estimating hit consequences of pollutant on ecosystem most really having made experiment in the conditions as much as possible close to the natural. In this article a very important problem of an accuracy and reliability of the results of trace elements determination in plants is also debated. As a result of carried investigations it was shown that the degree of cadmium extraction by hyacinth from contaminated natural water while maintaining the viability of the plants depends on the way of pollutant introducing into the reservoir and the maximum (about $79 \%$ ) value is observed in the case of it's gradual entry.
\end{abstract}

Keywords: contamination, water purification, environmental analysis, bioaccumulation.

\section{Introduction}

It is known that the consequences of natural waters pollution for the person are diverse: the number of fresh water sources is reduced; danger of a poisoning increases at the use in food of hydrocoles from the polluted reservoir; the risk of various diseases acquisition raises at water use in the economic purposes, etc. In this regard phytoremediation became an effective and economic methods of environments clearing due to the plant's ability to accumulate the metals at concentrations thousands times higher than background level have been found out. Biological essence of this phenomenon up to the end is not clear and actively studied now. The floating macrophyte water hyacinth, Eichhornia crassipes, (EC) is applied most often to sewage treatment of the industrial enterprises. The plant is capable to clean the reservoirs from many toxic substances, acquiring the contaminants from waters as food elements, basically through root system using the products of decomposition in the course of the ability to live [1]. EC actively accumulates $\mathrm{Pb}, \mathrm{Cd}, \mathrm{Cu}$, $\mathrm{Fe}, \mathrm{Mn}, \mathrm{Zn}, \mathrm{Cr}$ and other elements and substances. The distinction reasons in sink ability of plants in relation to different metals by the present moment precisely are not known. Among the inorganic pollutants cadmium is one of the most toxic heavy metals for living organisms which negatively effects on the environment and human health being accumulated throughout the food chain. It is supposed that $\mathrm{Cd}$ is actively taken as on chemical behavior in plants it is close to $\mathrm{Ca}$ and $\mathrm{Zn}$ - to the important components of many biologically active substances, as, for example, arsenic is capable to replace phosphorus in live systems.

There are a lot of publications which concerns of an assessing and application of hyacinth ability to heavy metals accumulation [2-10]. Unfortunately, more often this data is received as a result of the experiments spent in essentially different from the real environmental conditions. At the same time the behavior of chemical substances in natural ecosystems is described by a set of very complicated chemical, physical and biological processes, which can't be taken into account in laboratory conditions where it is possible to study the influence of separate factors on these processes. However the full picture of the transformations of the substances in natural system may strongly differ from the model. Most really to estimate hit consequences of pollutant on ecosystem having made experiment in the conditions as much as possible close to the natural. It allows the method of natural modeling offered by Odum, 1984 [11] consisting in a statement of natural experiments with the use of mesocosms, established directly in a reservoir into which one enters the set portion of investigated substance and then supervises the dynamics of its concentration. This approach in minicosms version has been realized in present work.

Another deserves attention problem is concerned a reliability of the data on the assessment of the element's accumulation by plants. Most often trace elements determination in EC and other macrophytes carried out using modern instrumental techniques in line with guidelines on the analysis of plant samples without regard to their matrix composition. Such an attitude may lead to a systematic error of analysis, and, as a consequence, incorrect evaluation of the actual coefficient of the element's accumulation by the plant. 
Thus, the goals of the present investigation were:

- to assess the correctness of the results of cadmium determination in samples of water hyacinth using independent analytical methods;

- to study the phytoremediation process in the presence of $\mathrm{EC}$ for the removal of cadmium from contaminated reservoir using minicosm approach;

- examine the dependence of cadmium accumulation by plants on the scheme of pollutant and additives introduction.

\section{Experimental}

\subsection{Field experiments description}

All experiments were carried out in summer 2009 in the field conditions on the river Yeltsovka (Novosibirsk region, Russia) served as a natural range. Young plants were grown in greenhouse (Institute of Cytology and Genetics of Siberian Branch of Russian Academy of Sciences) and in mid-June placed at disposal of field laboratory where were grown directly in the river close to the inflow to the reservoir of the Novosibirsk "artificial sea". The water reservoir where modeling experiments were realized refers to calcium-carbonate type with $\mathrm{pH}$ of 7.4-9.1 and the temperature range of $16-24^{\circ} \mathrm{C}$ in summer months [12].

Minicosm (M) represented a polyethylene capacity limited the allocated volume of 150-230 L of natural water from sides, whereas the top layers were in the same conditions as all reservoir, being treated thus to sunlight and atmosphere action, while the low layers had a contact with a sandy bottom included a little amount of silt. Six minicosms were arranged nearby the floating laboratory, in each of which three preliminary weighed water hyacinths were placed. Only mature plants with initial mass of 174-404 g were used in the experiments. One of these capacities (M6) with plants that were not exposed to metal served as a control, into other ones (M1-M5) the additives of cadmium and various fertilizers under the following scheme have been entered: $\mathrm{M} 1: \mathrm{Cd}\left(\mathrm{NO}_{3}\right)_{2}, 100 \mu \mathrm{g} \mathrm{L} \mathrm{L}^{-1}$, in a mode of additives on $20 \mu \mathrm{g}$ $\mathrm{L}^{-1}$ daily within 5 days; $\mathrm{M} 2: \mathrm{Cd}\left(\mathrm{NO}_{3}\right)_{2}, 100 \mu \mathrm{g} \mathrm{L}-1$, at a time; $\mathrm{M} 3: \mathrm{CdSO}_{4}, 100 \mu \mathrm{g} \mathrm{L}{ }^{-1}$, at a time; $\mathrm{M} 4: \mathrm{CdSO}_{4}, 100 \mu \mathrm{g}$ $\mathrm{L}^{-1}$, at a time plus phosphate fertilizer as $\mathrm{PO}_{4}^{3--}$ anion $\left(2 \mu \mathrm{g} \mathrm{L}^{-1}\right)$; $\mathrm{M} 5: \mathrm{CdSO}_{4}, 100 \mu \mathrm{g} \mathrm{L}{ }^{-1}$, at a time plus nitric fertilizers as $\mathrm{NO}_{3}^{-}$anion $\left(1 \mu \mathrm{g} \mathrm{L}{ }^{-1}\right)$.

The $\mathrm{pH}$, water and air temperature, cadmium and nitrate concentration in water were daily controlled in minicosms, the effect of weather factors was counted through the measuring of these parameters in the ambient river water. To control the level of the plant's vitality, the rate of their growth and the intensivity of nitrogen fixation as nitrate reductase activity (NRA) was measured every two-three days [13]. It has been established that during the whole experiment the concentration of nitrate ions varied in the range of $0.7-1.5 \mathrm{mg} \mathrm{L}^{-1}$ for various capacities, indicating the normal provision of water hyacinth with one of the major nutrients, NRA of the leaves of EC was at the level of 0,10$0,15 \mu \mathrm{M} \mathrm{g}^{-1} \mathrm{~h}^{-1}$, so the small variations in NRA suggest maintaining the viability of plants.

\subsection{Materials and instrumentation} Reagents

Cadmium nitrate $\mathrm{Cd}\left(\mathrm{NO}_{3}\right)_{2}$, cadmium sulfate $\mathrm{CdSO}_{4}$, phosphoric fertilizer as $\mathrm{Na}_{2} \mathrm{HPO}_{4}$, nitric fertilizer as $\mathrm{NaNO}_{3}$ of analytical grade were obtained from "Reachem" (Moscow, Russia), high purity sodium chloride $\mathrm{NaCl}$, nitric acid $\mathrm{HNO}_{3}$, hydrochloric acid $\mathrm{HCl}$, fluoric acid $\mathrm{HF}$ and boric acid $\mathrm{H}_{3} \mathrm{BO}_{3}$ were purchased from Merck (Germany). The multielemental water standard reference solutions MES-1 and MES-2 were obtain from the company "Skatt Ltd" (Novosibirsk, Russia).

Instruments

Field: the stripping voltammeter IVA-3 (Ekaterinburg, Russia) was applied to determine cadmium concentration in water samples. Nitrate-ion content in water was determined using ion-meter "Anion-410" (Novosibirsk, Russia) with ion-selective electrode ELIS-121 and a silver chloride electrode ESr-1021 as a reference one. Nitrate-reductasa activity was determined using in vivo method [14].

Laboratory: Atomic-emission spectrometer with direct current plasma source of excitation (DCP-arc-AES) PGS-2 (Carl Zeiss Jena, Germany) and atomic-emission spectrometer with inductively coupled plasma source of excitation (ICP-AES) iCAP 6000 (InterTechCorporation, USA) were used to determine the elements concentration in water hyacinth. For the digestion of the plants microwave accelerated reaction system Mars-5 (International Equipment Trading Ltd, USA) was used.

Analysis

To control the quality of the results of an evaluation of the metals content in plants the method of atomicemission spectrometry with two different sources of excitation was applied. The flame atomic-absorption spectrometry (FAAS) was used as a method for the intercomparison of the results of cadmium determination in the samples of water hyacinth by atomic emission spectrometry.

Sample preparation procedure for DCP-arc-AES analysis included the following steps: the blending of the sample with graphite powder (1:1); ash of the mixture at $450^{\circ} \mathrm{C}$ during 3 hours; cooling, homogenization, weighting and successive dilution with graphite powder supporting in each sub-sample a sodium chloride content at the level 
of $4 \% . \mathrm{NaCl}$. This additive allows enhancing the analytical signals intensities of the trace element's and, on the other hand, to provide the constancy of temperature and electron concentration in plasma source [15]. A series of the powder subsamples with dilutions of 2, 4, 8, 16, 32 (64 and 128 for the roots) were prepared. The matrix effect considered eliminated if for two consecutive dilutions the distinctions between two values of detected concentration were inside of the confidential interval for the average value.

DCP-arc-AES analysis: graphite anode with a cavity of $4 \mathrm{~mm}$ in diameter and graphite cathode of conical form; slight width $20 \mu \mathrm{m}$; direct current $13 \mathrm{~A}$; spectra exposition time $18 \mathrm{sec}$. Spectra registration was performed using a solid state photodiode array. A unified series of reference samples on the base of graphite powder with sodium chloride (4\%) as a strengthening additive containing elements under investigation at the level of $0.014-33.0 \mathrm{mg} \mathrm{kg}^{-1} \mathrm{was} \mathrm{used}$ [15].

Sample preparation procedure for ICP-AES analysis was carried in microwave assisted digestion system using PFA-vessels where $0.1 \mathrm{~g}$ of the sample was mixed with $5 \mathrm{~mL}$ of nitric acid, $1 \mathrm{~mL}$ of hydrochloric acid and $0,4 \mathrm{~mL}$ of fluoric acid. After digestion and cooling $3 \mathrm{~mL}$ of boric acid solution (4\%) was added into the vessel to destroy the insoluble fluoric compounds of calcium and aluminum, then the resulting solution was diluted to the volume of $25 \mathrm{~mL}$. To eliminate the matrix effect scandium nitrate was added to the probe as internal standard at the level of $0.5 \mathrm{mg} \cdot \mathrm{L}^{-1}$. The working parameters of the microwave oven are given in Table 1.

Table 1

Digestion program used for the sample preparation procedure in DCP-AES.

\begin{tabular}{|cccc|}
\hline Stage & Temperature, $\mathbf{0 C}$ & Power, W per vessel & Duration, min. \\
\hline I & 90 & 120 & 10 \\
\hline II & 150 & 120 & 30 \\
\hline III & 180 & 120 & 5 \\
\hline
\end{tabular}

ICP-AES-analysis working parameters: power supply $1150 \mathrm{~W}$; argon flows, $\mathrm{L} \cdot \mathrm{min}^{-1}: 0.7$ for the nebulizer, auxiliary -0.5 , cooling -12 . The data acquiescing and processing was provided by iTEVA (InterTech corporation) software. The calibration was done with the use of water solutions of the metal's salts mixture in the concentration range of $0.01-10 \mathrm{mg} \cdot \mathrm{L}^{-1}$.

Sample preparation procedure for FAAS analysis was conducted using open vessels according to the scheme: 0.1-0.5 g of the sample was placed into the porcelain crucible and ashed in the muffle at $480-500^{\circ} \mathrm{C}$, the ash was then dissolved in $5 \mathrm{~mL}$ of $\mathrm{HNO}_{3}$ under the aging during 12 hours, heated until white vapor, then $5 \mathrm{~mL}$ of $\mathrm{HF}$ was added and the mixture was evaporated to the dry residue, which was then dissolved in $10 \mathrm{~mL}$ of water. The analysis was done using Perkin Elmer 3030B instrument.

\section{Results and discussion}

The results of cadmium determination in water hyacinth using two independent AES methods with different sources of excitation for all minicosms are given in Table 2. It is seen that the results of DCP-arc-AES method demonstrates the systematic understatement comparatively with ICP-AES analysis most pronounced for the roots; this discrepancy may be caused by two reasons: cadmium losses during dry ash procedure or incomplete elimination of the matrix effect using the above mentioned successive dilution approach. To clarify the question concerning sample pretreatment procedure the residues of the roots, leaves and stems after dry ash were digested in the microwave oven and then the solutions were analyzed by ICP-AES. The data produced are shown in Fig. 1 by the example of the samples from minicosm M3, it is seen that a volatilization of cadmium compounds when being heated at $450^{\circ} \mathrm{C}$ during ash is insignificant. It may be also suggested that under stating of the DCP-arc-AES this effect may result from incomplete accounting of the matrix effects using successive addition approach.

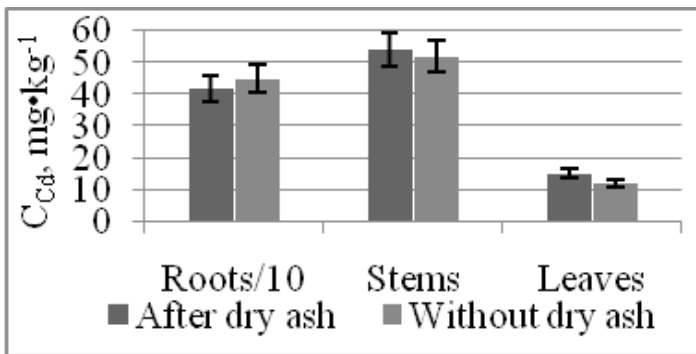

Fig. 1. The results of cadmium determination in various parts of the plant by ICP-AES using different sample preparation procedures. 
To exclude the influence of organic matter on the results of DCP-arc-AES-analysis above mentioned microwave assisted samples preparation procedure was applied and the obtained solutions were analyzed using DCP-arc-AES being evaporated on graphite powder in the presence of $4 \% \mathrm{NaCl}$. As can be seen from Fig. 2 in this case a significant differences in the results obtained by different methods is observed which is most pronounced for the roots. It can be assumed that the matrix effect is caused by the presence of major elements at the concentration level two or tree order of magnitudes higher than for the analyte. Unfortunately there are no published data concerning the mineral components content in water hyacinth. We evaluated the contents of $\mathrm{Si}, \mathrm{Mg}, \mathrm{Fe}, \mathrm{Na}, \mathrm{K}$ and $\mathrm{Al}$ in this plant using ICP-AES and compared them with those for other plants including the floating one which are produced as the standard reference materials (SRMs) at the Vinogradov Institute of Geochemistry (Irkutsk, Russia) (Table 3). It is clear that hyacinth in its mineral composition sufficiently differs from the other plants. Probably, the depressing influence on the analytical signal of cadmium is associated with the cumulative effect of the major elements: $\mathrm{Si}, \mathrm{Al}, \mathrm{Na}, \mathrm{K}$ and others.

Table 2

Cadmium distribution between the parts of EC for the different minicosms according to the methods of DCP-arc-AES and ICP-AES, $\mathrm{mg} \cdot \mathrm{kg}-1$ (dry weight), $\mathrm{P}=\mathbf{0 . 9 5}$. $n=3$ (the average of the results for three plants for each minicosm are presented).

\begin{tabular}{|c|c|c|}
\hline \multicolumn{3}{|c|}{ Cd concentration (the average of three results) } \\
\hline Part of the plant & DCP-arc-AES & ICP-AES \\
\hline \multicolumn{3}{|c|}{ Minicosm M1 (the rest Cd concentration in water $0.01 \pm 0.0008 \mathrm{mg} \cdot \mathrm{L}^{-1}$ ) } \\
\hline Roots & $360 \pm 50$ & $730 \pm 40$ \\
\hline Stems & $72 \pm 9$ & $71 \pm 5$ \\
\hline Leaves & $13 \pm 3$ & $20 \pm 2$ \\
\hline \multicolumn{3}{|c|}{ Minicosm M2 (the rest Cd concentration in water $0.005 \pm 0.001 \mathrm{mg} \cdot \mathrm{L}-1)$} \\
\hline Roots & $240 \pm 30$ & $500 \pm 20$ \\
\hline Stems & $52 \pm 7$ & $74 \pm 5$ \\
\hline Leaves & $12 \pm 3$ & $11 \pm 1$ \\
\hline \multicolumn{3}{|c|}{ Minicosm M3 (the rest Cd concentration in water $0.007 \pm 0.001 \mathrm{mg} \cdot \mathrm{L}^{-1}$ ) } \\
\hline Roots & $100 \pm 20$ & $520 \pm 20$ \\
\hline Stems & $37 \pm 5$ & $58 \pm 4$ \\
\hline Leaves & $16 \pm 3$ & $11 \pm 1$ \\
\hline \multicolumn{3}{|c|}{ Minicosm M4 (the rest Cd concentration in water $0.005 \pm 0.001 \mathrm{mg} \cdot \mathrm{L}^{-1}$ ) } \\
\hline Roots & $240 \pm 40$ & $420 \pm 20$ \\
\hline Stems & $49 \pm 7$ & $67 \pm 5$ \\
\hline Leaves & $13 \pm 3$ & $13 \pm 1$ \\
\hline \multicolumn{3}{|c|}{ Minicosm M5 (the rest Cd concentration in water $0.005 \pm 0.001 \mathrm{mg} \cdot \mathrm{L}^{-1}$ ) } \\
\hline Roots & $220 \pm 30$ & $350 \pm 20$ \\
\hline Stems & $49 \pm 7$ & $59 \pm 4$ \\
\hline Leaves & $11 \pm 3$ & $13 \pm 1$ \\
\hline \multicolumn{3}{|c|}{ Minicosm M6 (the rest Cd concentration in water $<0.0001 \mathrm{mg} \cdot \mathrm{L}^{-1}$ ) } \\
\hline Roots & $7 \pm 4$ & $5 \pm 0.7$ \\
\hline Stems & $3.4 \pm 1.3$ & $3.0 \pm 0.4$ \\
\hline Leaves & $0.2 \pm 0.1$ & $0.3 \pm 0.03$ \\
\hline
\end{tabular}

The major elements content in different types of the plants, $\mathrm{mg} \mathrm{kg}^{-1}$.

\begin{tabular}{|lcccccc|}
\hline \multicolumn{1}{l}{ Elant } & $\mathrm{Si}$ & $\mathrm{Fe}$ & $\mathrm{Mg}$ & $\mathrm{K}$ & $\mathrm{Na}$ & $\mathrm{Al}$ \\
\hline Water hyacinth & $1.8 \pm 0.1$ & $0.4 \pm 0.08$ & $0.57 \pm 0.08$ & $5.5 \pm 04$ & $4.9 \pm 0.2$ & $0.30 \pm 0.05$ \\
\hline Elodea Canadensis & - & $0.26 \pm 0.01$ & $0.32 \pm 0.02$ & $3.22 \pm 0.16$ & $0.69 \pm 0.05$ & $0.010 \pm 0.01$ \\
\hline Birch leaves & $0.40 \pm 0.07$ & $0.073 \pm 0.007$ & $0.44 \pm 0.03$ & $0.71 \pm 0.04$ & $0.018 \pm 0.003$ & $0.083 \pm 0.01$ \\
\hline
\end{tabular}

Thus, the data obtained by ICP-AES technique were considered as the accurate results. To control the correctness of cadmium determination by ICP-AES in the samples of water hyacinth the inter-comparison with the results of independent method (FAAS) was applied. The results were compared with the use of t-criteria [16] calculated in accordance with the formulas: 
$\mathrm{S}_{0}{ }^{2}=\left(\left(\mathrm{n}_{1}-1\right) \cdot \mathrm{S}_{1}^{2}+\left(\mathrm{n}_{2}-1\right) \cdot \mathrm{S}_{2}^{2}\right) /\left(\mathrm{n}_{1}+\mathrm{n}_{2}-2\right)$, where $\mathrm{S}_{1}$ and $\mathrm{S}_{2}$-dispersions for two results $\mathrm{C}_{1}$ and $\mathrm{C}_{2}$ of independent methods; $n_{1}$ and $n_{2}-$ the number of parallel results for two methods;

$$
\mathrm{t}_{\exp } \cdot=\left|\mathrm{C}_{1}-\mathrm{C}_{2}\right| \cdot\left(\mathrm{n}_{1} \cdot \mathrm{n}_{2}\right)^{0.5} / \mathrm{S}_{0} \cdot\left(\mathrm{n}_{1}+\mathrm{n}_{2}\right)^{0.5} \text {. }
$$

It is seen (Table 4) that the results of cadmium determination for the roots, stems and leaves are coinciding inside the confidence interval which confirms their reliability.

The comparison of results of cadmium determination in water hyacinth using independent analytical methods. $n 1=n 2=3, P=0.95 ; t_{\text {theor }}=3.18$.

\begin{tabular}{|c|c|c|c|}
\hline \multicolumn{4}{|c|}{ Cadmium concentration, $\mathrm{mg} \cdot \mathrm{kg}^{-1}$} \\
\hline Sample & ICP-AES(1) & FAAS (2) & $\mathrm{t}_{\text {experimental }}$ \\
\hline & $440 \pm 90$ & $500 \pm 180$ & 2.58 \\
\hline Roots & $750 \pm 130$ & $730 \pm 230$ & 0.59 \\
\hline Leaves & $21 \pm 3$ & $21 \pm 5$ & 0.0 \\
\hline Stems & $58 \pm 12$ & $60 \pm 12$ & 0.91 \\
\hline
\end{tabular}

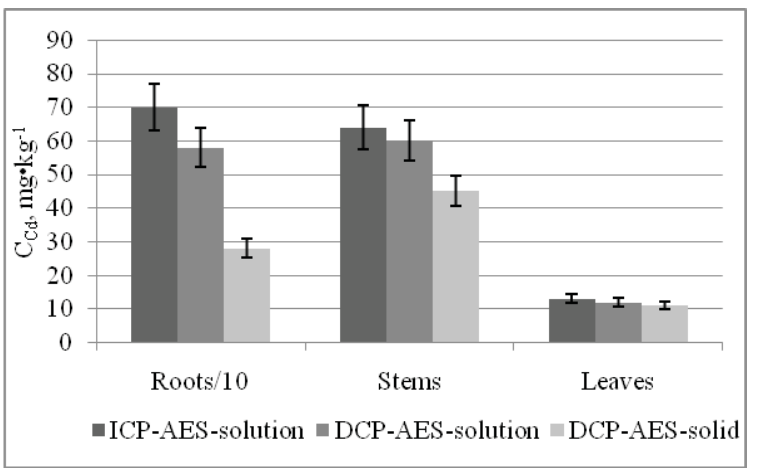

Fig. 2. The results of cadmium determination in various parts of the plant after microwave digestion of the samples.

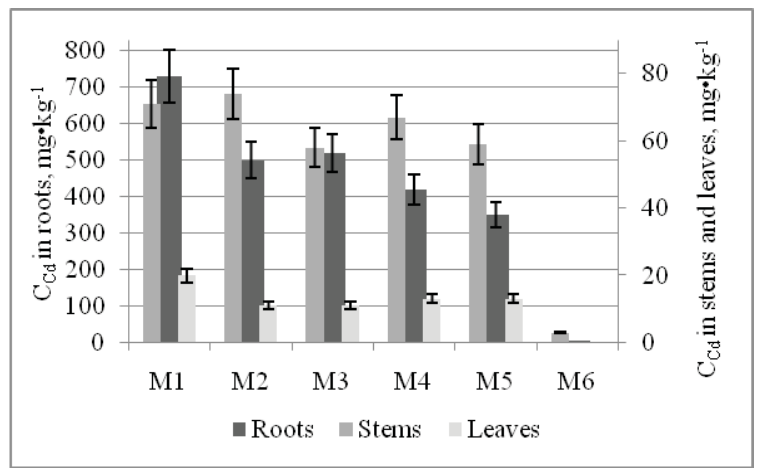

Fig. 3. Cadmium accumulation by the roots, shoots and leaves of the plants in different minicosms.

According the diagram (Fig. 3) it may be concluded that cadmium is mainly accumulated in roots that agree with the data of other researchers; the highest degree of cadmium uptake is observed in the plants of minicosm M1 with a droplet cadmium addition; moreover, it considerably exceeded these values for the other minicosms when the same Cd compounds were introduced of $100 \mu \mathrm{g} \mathrm{L} \mathrm{L}^{-1}$ at a time; cadmium accumulation by plants in minicosms with one time addition was lower in minicosm M3 (cadmium as sulphate salt) then in other two (cadmium as nitrate salt); the introduction of sodium hydrophosphate as fertilizer stimulated cadmium uptake in minicosm M4 while nitrate fertilizer (minicosm M5) was not effective.

The data on the accumulation of cadmium by water hyacinth dependently on pollutant introduction scheme and the presence of additives are summarized in Table 5. It is also seen that cadmium extraction by the plants from the water environment corresponds to the range of 50-79 \%. As for the rest cadmium content in water to the end of experiment (8th day) it didn't exceed $20 \%$ of initial quantity. One may suggest that there are other channels of cadmium removal from water, among which the sorption on the suspended particles and an uptake by the water biota may supposed as the most essential. 


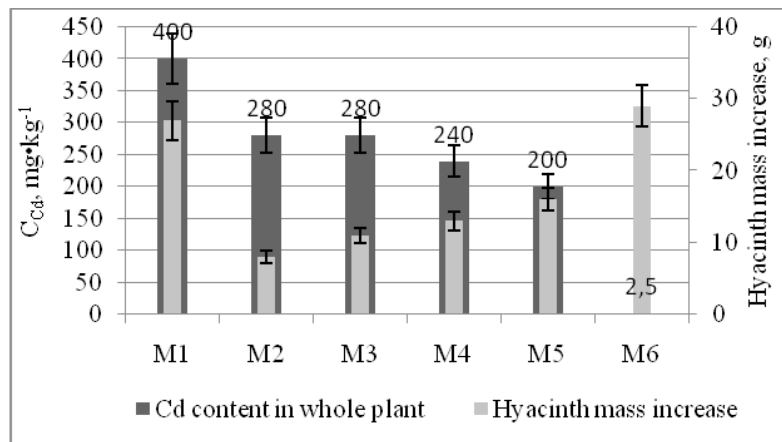

Fig. 4. Cadmium uptake and hyacinth mass increase in minicosms.

Table 5

Accumulation of cadmium by a water hyacinth under different conditions.

The results are presented for three plants for each minicosm.

\begin{tabular}{|ccccccc|}
\hline $\begin{array}{c}\text { Mini- } \\
\text { cosm } \\
\text { number }\end{array}$ & $\begin{array}{c}\text { Experimental } \\
\text { conditions }\end{array}$ & $\begin{array}{c}\text { Total } \\
\text { amount } \\
\text { of Cd } \\
\text { introduced, } \\
\text { mg }\end{array}$ & $\begin{array}{c}\text { The rest } \\
\text { amount of } \mathbf{C d} \\
\text { in minicosm, } \\
\text { mg }\end{array}$ & $\begin{array}{c}\text { Cadmium } \\
\text { concentration } \\
\text { in whole plant, } \\
\text { mg.kg-1 }\end{array}$ & $\begin{array}{c}\text { Total } \\
\text { cadmium } \\
\text { content in } \\
\text { the plant, mg }\end{array}$ & $\begin{array}{c}\text { The portion of } \\
\text { Cd uptake by } \\
\text { plant, \% }\end{array}$ \\
\hline $\mathrm{M} 1$ & $\mathrm{Cd}\left(\mathrm{NO}_{3}\right)_{2}: 20 \mu \mathrm{g} \cdot \mathrm{L}^{-1} \times 5$ & $20.5 \pm 1.6$ & $2.1 \pm 0.2$ & $400 \pm 70$ & $13 \pm 2$ & $71 \pm 14$ \\
\hline $\mathrm{M} 2$ & $\mathrm{Cd}\left(\mathrm{NO}_{3}\right)_{2}: 100 \mu \mathrm{g} \cdot \mathrm{L}^{-1}$ & $23.0 \pm 1.5$ & $1.2 \pm 0.02$ & $400 \pm 70$ & $11 \pm 1$ & $50 \pm 4$ \\
\hline $\mathrm{M} 3$ & $\mathrm{Cd}\left(\mathrm{SO}_{4}\right)_{2}: 100 \mu \mathrm{g} \cdot \mathrm{L}^{-1}$ & $15.0 \pm 2.0$ & $1.1 \pm 0.02$ & $400 \pm 70$ & $11 \pm 1$ & $79 \pm 13$ \\
\hline $\mathrm{M} 4$ & $\begin{array}{c}\mathrm{Cd}\left(\mathrm{SO}_{4}\right)_{2} \\
100 \mu \mathrm{g} \cdot \mathrm{L}^{-1}+\mathrm{Na}_{2} \mathrm{HPO}_{4}\end{array}$ & $20.0 \pm 1.5$ & $1.1 \pm 0.02$ & $400 \pm 70$ & $13 \pm 2$ & $69 \pm 10$ \\
\hline $\mathrm{M} 5$ & $\begin{array}{c}\mathrm{Cd}\left(\mathrm{SO}_{4}\right)_{2} \\
100 \mu \mathrm{g} \cdot \mathrm{L}^{-1}+\mathrm{NaNO}_{3}\end{array}$ & $20.0 \pm 1.5$ & $0.1 \pm 0.03$ & $400 \pm 70$ & $10 \pm 2$ & $50 \pm 10$ \\
\hline
\end{tabular}

The increase in weight of plants was observed in all minicosms. It means that the capacity of the hyacinth to absorb the pollutant is limited by their ability to self-preservation. Nevertheless, it appears (Fig. 4) that plant growth was depressed in all cases when pollutant was added into the minicosm at the level of $100 \mu \mathrm{g} \cdot \mathrm{L}^{-1}$ at a time irrespective of the salt type and the presence of fertilizers. On the other hand the cadmium influence was practically not exposed in minicosm M1 with droplet addition of $20 \mu \mathrm{g} \cdot \mathrm{L}^{-1}$ cadmium daily within 5 days. In accordance with the published data [17] a decrease of cadmium toxicity for some plants is caused due to the formation of the complexes with phytohelatins or flavonoids which have been discovered in water hyacinth [18]. Hence we can assume that because such transformation process takes place the regime of cadmium gradual addition is more sparing for the plant.

\section{Conclusion}

The results of experiment carried out in frames of natural modeling approach allows us to conclude, that the water hyacinth capacity of growth and metal uptake strongly depend on the weather conditions, exposure mode and the presence of other constituents, herewith the basic part of heavy metal collects in the roots (about $70 \%$ from absorbed). Much more active pollutant accumulation is observed when gradual additions mode used, where vital activity of a plant leads to higher gain of its biomass. It is noticed that the type of metal compound influences its accumulation by plant, however, to a lesser degree, than distinction in additive modes.

\section{Acknowledgements}

The authors are grateful to Professor Veprev S.G. and Nechiporenko N.N. (Institute of Cytology and Genetics, Siberian Branch of Russian Academy of Sciences) for providing of the samples of water hyacinth and Dr. Badmaeva G.O. (Institute of Geology and Mineralogy, Siberian Branch of Russian Academy of Sciences) for the results of cadmium determination in hyacinth by FAAS.

\section{References}

[1]. Watai, H.; Miyazaki, T.; Fujikawa, T.; Mizoguchi, M. The Smithsonian. NASA Astrophysics Data System. 2004. 
[2]. Tokunaga, K.; Furuta, N.; Morimoto, M. J. Hygrol. Chem. 1976, 22, 234-239.

[3]. Salt, D. E. et al. Biotechnology. 1995, 13, 468-474.

[4]. Das, P.; Summary, S.; Route, G. R. Environ. Pollut. 1997, 98, 19-36.

[5]. Gupta, G. C. J. Environ. Health. 1980, 43, 80-82.

[6]. Zayed, A.; Gowthaman S.; Terry N. Environ. Qual. 1998, 27, 71.

[7]. Fett, J. P.; Cambraia, J.; Oliva, M. A. et al. J. Plant. Nutr. 1994, 17, 1219-1230.

[8]. Maine, M. A.; Duarte, M. V.; Sune, N. L. Wat. Res. 2001, 35, 2629-2634.

[9]. Xiaomei, L.; Maleeya, K. R.; Prayad, P.; Homyak, K. Science Asia. 2004, 30, 93-103.

[10]. Dhote, S.; Dixit, S. Environ. Monit. Asses. 2009, 152, 149-153.

[11]. Odum, E. P. Bioscience. 1984, 34, 558-562.

[12]. Vorotnikov, V. A.; Kuskovsky, V. S.; Anoshin, G. N. Obskoy vestnik. 1999, 3-4, 48-61 (rus.).

[13]. Lowe, R.; Evans, H. Biochim. Biophys. Acta. 1964, 85, 377.

[14]. Ovcharenko, G. A. et al. Fiziologiya rastenii. 1990, 37, 642-649 (rus.).

[15]. Yudelevich, I. G.; Buyanova, L. M.; Shelpakova, I. R. Khimiko-spectralnii analisvestsestv visokoi chistoti (Russ.), Novosibirsk: Nauka, 1980.

[16]. Doerfel, K. Statistika v analititseskoi khimii. Moscow: Mir, 1969 (rus.).

[17]. Dubinina, U. U.; Dultzeva, G. G.; Palesskii, S. V.; Skubnevskaya, G. I. Ecologicheskaya khimiya. 2003, 12, 4146 (rus.).

[18]. Nyananyo, B. L.; Gijo, A. H.; Ogamba, E. N. J. Appl. Sci. Environ. 2007, 11(3), 133-137. 